\title{
ESTRUTURA E AGÊNCIA NAS RELAÇÕES INTERNACIONAIS: CONSTRUÇÃO DO ESTADO E A EVOLUÇÃO DO SISTEMA POLÍTICO INTERNACIONAL
}

\author{
Marco Aurélio Chaves Cepik ${ }^{1}$ \\ Pedro Txai Brancher ${ }^{2}$
}

\section{Introdução}

Como a competição ${ }^{3}$ entre os agentes produz efeitos nos processos evolutivos ${ }^{4}$ dos sistemas políticos internacionais? A resposta para essa questão exige primeiramente a delimitação ontológica dos objetos de análises. Será

I Professor Associado do Departamento de Economia e Relações Internacionais (DERI), Universidade Federal do Rio Grande do Sul (UFRGS). E-mail: marco.cepik@ufrgs.br

2 Doutorando em Ciência Política pelo Instituto de Estudos Sociais e Políticos (IESP), Universidade Estadual do Rio de Janeiro (UERJ). E-mail: pedro.txai@gmail.com

3 Neste trabalho, competição e conflitos de interesses serão tratados como sinônimos e são definidos como: "uma forma de interação entre indivíduos, grupos, organizações e coletividades que implica choques para o acesso e a distribuição de recursos escassos" (Pasquino I998, 225). Ademais, salienta-se que não se objetiva identificar as causas dos conflitos, mas sim suas consequências para o processo evolutivo dos objetos de análise delimitados.

4 Por evolução, compreende-se a sequência de transformações nos componentes dos sistemas sociais, não implicando o conteúdo normativo de tais mudanças (Vasconcellos 2013, 85).

5 É importante ressaltar que se entende "sistemas" como os modelos lógicos que representam entidades formadas por conjuntos de elementos em interação (Bertuglia e Vaio 2005, 3). Logo, a definição ontológica de um sistema trata dos "critérios de distinção que assinalam aquilo de que falamos e especifica suas propriedades como ente, unidade ou objeto" (Maturana e Varela 2005,47 ). Contudo, defini-los ontologicamente não implica argumentar que a realidade física e social seja um sistema de fato (Wight, 2006). Em outras palavras, a validade analítica da instanciação e operacionalização de tais modelos será sempre sujeita a condições empíricas. Conforme argumenta Reis (1997, I9): "Se essas condições se observam ou não, de maneira a podermos descrever as sociedades que estudamos a partir daqueles modelos, ou ainda se o sistema tal como o definimos descreve adequadamente o conjunto de fenômenos que pretendemos analisar, são questões empíricas, que ora responderemos afirmativamente, ora negati- 
definido que sistemas políticos internacionais (SPI) possuem uma estrutura anárquica, sendo compostos primariamente pelas interações ${ }^{6}$ que envolvem o uso ou ameaça do uso da força entre organizações políticas que não estão submetidas a uma autoridade superior capaz de impor limites para o comportamento dos agentes (Waltz I979; Buzan e Little 2000, 92). Sistemas políticos nacionais ${ }^{7}$ (SPN), por outro lado, possuem uma estrutura hierárquica, sendo formados pelas interações entre indivíduos e organizações em territórios nos quais há uma organização que concentra os meios coercitivos e impõe limites para o comportamento dos agentes (Waltz I979; Elias I993; Geuss 200I). Por sua vez, Estados ${ }^{8}$ serão tanto as unidades constituintes dos sistemas políticos internacionais como as organizações que monopolizam os meios coercitivos nos sistemas políticos nacionais (Tilly I996; Hui 2005; Levy e Thompson 2OII).

Pressupõe-se que as variações nos graus de concentração dos meios coercitivos $^{9}$ distinguem a natureza e as consequências da competição entre os agentes de cada sistema (Waltz I979, 92). Argumenta-se que a ausência de governo central faz com que a competição nos sistemas políticos internacionais envolva a sobrevivência das organizações políticas estatais, o que, consequentemente, constrange as possibilidades de aumento da especialização funcional entre elas. Por outro lado, a concentração dos meios de coerção nos sistemas políticos nacionais impõe limites ao uso da força nos conflitos de interesse, o que, por sua vez, reduz a insegurança dos agentes e permite o

vamente. Mas podemos perfeitamente, em bases puramente lógico-analíticas, discutir se tais ou tais condições são mesmo ou não necessárias à reprodução de um sistema tal como definido em determinada obra".

6 Por interação, entende-se o conjunto de relações que torna as partes de um sistema interdependentes entre si.

7 Ressalta-se que o conceito de sistemas políticos nacionais não se refere somente aos sistemas sociais em que há presença de organizações políticas denominadas Estados-nação. O conceito será utilizado para caracterizar qualquer sistema social em que houve a monopolização dos meios de coerção por uma organização estatal, seja essa organização uma cidade-estado, um império, um reino, etc.

8 Serão utilizados os termos organizações políticas, unidades, estados e agentes como sinônimos dos componentes dos sistemas políticos internacionais. Ademais, referir-se-á a estados com "e" minúsculo quando se estiver tratando de organizações políticas que exercem ou visam exercer o controle dos meios de força em determinado território. Nesse sentido, o termo pode representar Impérios, cidades-estados, ligas de cidade, reinos, etc. O termo Estado com o "E" maiúsculo será utilizado quando se referir às organizações políticas formadas após o fim da ordem feudal na Europa Ocidental. Ou seja, aos Estados Nacionais que se constituem como a organização política predominante em todos os continentes na atualidade.

9 Por coerção, compreende-se a imposição da vontade de um agente sobre o outro por meio do uso ou ameaça do uso da força. Meios coercitivos consistem nos recursos materiais necessários para que um agente exerça a coerção sobre outro (Giddens 200I, 37). 
incremento da divisão do trabalho no sistema (Elias I993).

De acordo com os agentes e meios envolvidos, três dimensões de competição social serão identificadas: a Competição Internacional, caracterizada pelas interações competitivas que compreendem o uso ou ameaça do uso da força entre organizações políticas nos SPI, e que envolve as capacidades materiais e os elementos organizacionais que sustentam o emprego da força no âmbito internacional; a Construção do Estado ${ }^{\mathrm{IO}}$, caracterizada pelas interações competitivas entre o estado, organizações e indivíduos em torno da extração e controle dos recursos nos SPN, e que concerne às formas pelas quais as organizações políticas alcançam o monopólio dos meios de coerção e bem estabelecem legitimidade para sua dominação em um território delimitado; e, por último, a Concorrência Regulada, caracterizada pelas disputas entre organizações não estatais e indivíduos em relação à distribuição das probabilidades de vida dentro dos sistemas políticos nacionai ${ }^{\text {II }}$, e que envolve as maneiras que a regulação imposta pelos estados influencia na distribuição das probabilidades de vida dentro dos SPN.

Delimitados os objetos de análise, define-se como hipótese de trabalho que os resultados das interações entre os agentes segundo estratégias por eles escolhidas para enfrentar a competição com que se deparam causam mudanças na estrutura dos sistemas políticos internacionais e nas características das organizações políticas estatais.

Para demonstrar o argumento, o artigo se divide em duas seções. A primeira questiona em que condições a competição entre os estados engendra mecanismos que reforçam processos de concentração dos meios coercitivos nos sistemas políticos internacionais? Primeiramente, avalia-se que os pressupostos da anarquia e da baixa especialização funcional presentes no modelo proposto por Kenneth Waltz (I979) não implicam necessariamente a existência de apenas um mecanismo atuando nos SPI. De fato, argumenta-se que, em função dos sistemas políticos internacionais serem sistemas abertos, as interações entre seus agentes permitem a emergência ${ }^{12}$ de mecanismos

Io O termo "construção do estado" será empregado para caracterizar os conflitos de interesses entre estado, organizações não estatais e indivíduos dentro dos sistemas políticos nacionais. O termo "formação do estado" será empregado para caracterizar processos históricos nos quais organizações políticas se formaram.

II Desse modo, três fontes de literatura serão avaliadas. O entendimento acerca de como a estrutura dos sistemas políticos internacionais constrange o comportamento das unidades Teoria das Relações Internacionais - será complementado pela ponderação sobre como os recursos são produzidos e extraídos nos sistemas políticos nacionais - Sociologia Histórica -, bem como pela análise dos condicionantes logísticos e operacionais que sustentam a atividade da guerra - Estudos Estratégicos.

I2 Emergência é o processo no qual fenômenos que não podem ser apreendidos a partir da 
concorrentes, que podem favorecer tanto a concentração quanto a distribuição dos meios de coerção. Por fim, analisa-se o modelo explicativo proposto por Victoria Tin-bor Hui (2005) para a transformação do sistema de reinos na China para um império sob a dinastia Qin durante o período de 656-22I a.C.

A segunda seção questiona como a competição internacional influencia as dimensões da construção do estado e da concorrência regulada dentro dos sistemas políticos nacionais? Primeiramente, distingue-se ontologicamente os estados dos demais agentes pertencentes aos SPN. Considera-se que a especificidade das organizações políticas estatais consiste na execução de três atividades: monopolização dos meios de coerção dentro do SPN; imposição de ordens de regulação comportamental aos demais agentes e defesa contra outras organizações políticas (Tilly I996; Waltz I979; Giddens 200I).

Em seguida, argumenta-se que as ordens reguladoras não são neutras em relação à concorrência regulada. De fato, elas tenderão a favorecer indivíduos e organizações que dominam os recursos necessários para que os estados efetuem suas finalidades (North, Wallis e Weingast 2009). Além disso, na medida em que os agentes estatais concentrarem os recursos necessários para a realização dessas três tarefas, eles terão maior autonomia em relação às demais organizações dos SPN. Por sua vez, caso esses recursos estiverem concentrados em outros atores, as intervenções estatais tenderão a refletir os interesses daqueles atores. Por fim, analisa-se o modelo explicativo proposto por Tilly (I975; I985; I996) acerca dos efeitos da competição internacional no processo de formação e consolidação dos Estados-nação na Europa.

\section{Sistemas Políticos Internacionais: competição e evolução da estrutura}

A compreensão da natureza da competição em um sistema social exige a delimitação ontológica de três elementos: fronteiras, mecanismos e estrutura (Gilpin I98I). Fronteiras referem-se tanto às condições necessárias para a inclusão de componentes ao modelo, quanto as interações entre o sistema e seu ambiente. Em outras palavras, à delimitação do que se insere e do que se exclui do sistema, o que permite então entender como variáveis exógenas interferem em seu funcionamento (Maturana e Varela 2005). Mecanismos são as maneiras plausíveis e frequentemente observadas em que processos de mudança ocorrem (Pierson 2000).

soma dos comportamentos isolados das unidades constituintes surgem no nível sistêmico (Holland 20I2). Não há necessidade de planejamento central. Padrões de organização emergem das interações entre os agentes e se tornam irredutíveis a elas (Abbot 2006).

162 Austral: Revista Brasileira de Estratégia e Relações Internacionais v.6, n.11, Jan./Jun. 2017 
A estrutura se refere ao modo como as unidades estão ordenadas em relação umas às outras. O nível estrutural indica: "uma descrição geral sobre a organização de uma sociedade escrita em termos do posicionamento das unidades ao invés de seus atributos" (Waltz I979, 9, tradução nossa). Identificar os elementos que compõem a estrutura importa para a avaliação dos constrangimentos impostos às unidades, bem como para formulação de hipóteses acerca de seus comportamentos (Carlsnaes I992).

Delimita-se como condições necessárias para o pertencimento de uma unidade aos SPI que ela seja: i) uma organização política que concentre os meios de coerção em um território delimitado e ii) possua capacidade de ação em âmbito internacional (Waltz I979; Rosenau I997; Jervis I997; Cusack e Stoll I994) $)^{13}$. Ou seja, os agentes nos SPI são “entidades compostas de vários subgrupos, organizações, comunidades e muitos indivíduos suficientemente coesos para possuírem qualidade de agência" (Buzan e Little 2000, IoI, tradução nossa). Isso significa que as unidades (agregados de instituições e indivíduos) dos SPI são capazes de interpretar, planejar e executar ações que não derivam apenas de constrangimentos e incentivos estruturais ${ }^{\mathrm{I} 4}$ (Friedman e Starr i997).

No entanto, apesar de se reconhecer que estados se relacionam de inúmeras maneiras, não serão incluídos todos os tipos de interações em nossa análise. Isso porque, conforme salientam Barry Buzan e Richard Little (2000, 76, tradução nossa), "diferentes tipos de interação, e, portanto, diferentes tipos de unidades se tornam mais - ou menos - proeminentes dependendo da lente setorial utilizada para analisar o sistema internacional". Logo, mesmo reconhecendo a importância de interações culturais e econômicas para as relações internacionais (Watson I992; Wendt I999; Arrighi 2010), restringe-se o modelo às interações que envolvem a coerção, ou seja, o uso ou ameaça do uso de força (Geuss 200I $)^{15}$.

A estrutura do sistema será descrita com base em dois pressupostos presentes no modelo proposto por Kenneth Waltz (1979). O primeiro é que os sistemas políticos internacionais são ontologicamente anárquicos, ou

I3 A ontologia e os processos de evolução dos agentes dos sistemas políticos internacionais serão avaliados na próxima seção. Por ora, importa salientar que a capacidade de ação autônoma na esfera internacional é condição necessária para o pertencimento de uma organização política no modelo de SPI deste estudo (Waltz I979; Buzan I984; Watson I992).

I4 Assim como Waltz (I979), parte-se do pressuposto de que, apesar de possuírem diversos objetivos, todos os estados buscam primeiramente assegurar sua sobrevivência nos sistemas políticos internacionais.

I5 Interações econômicas culturais serão avaliadas como variáveis exógenas ao modelo, ou seja, na medida em que influenciarem o modo como as interações competitivas que envolvem o uso ou ameaça do uso da força entre os estados influenciam a evolução da estrutura dos SPI. 
seja, não possuem autoridade central. Tal pressuposto deriva da concepção de que a capacidade de ação das organizações políticas no âmbito internacional depende de sua prerrogativa (e de sua capacidade) para definir e executar autonomamente ações externas ${ }^{16}$. Por conta disso, a distribuição dos meios de

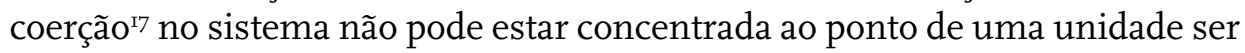
capaz de regular totalmente as ações das demais. Em outras palavras, é óbvio que sem capacidade de ação não há agência (Buzan i984).

A descentralização dos meios de força em um SPI gera, em si mesma, incerteza acerca do comportamento de seus agentes. Ou seja, a ausência de governo central faz com que a competição internacional ${ }^{18}$ seja permeada pela constante incompletude informacional acerca das intenções e reais capacidades das unidades. Assim, somente possuindo os meios de força necessários para se defenderem dos demais é que os estados podem assegurar a continuidade de sua própria existência (Waltz I979, 74) I9 $^{\text {. }}$

Delimitada a ontologia anárquica da estrutura dos SPI, pode-se deduzir como opera o mecanismo da socialização-seleção em seu processo evolutivo. De acordo com Checkel $(2006,364)$ : "socialização e seleção se referem ao processo de indução de novos atores às normas, regras e padrões de comportamento de uma determinada comunidade". Isto é, a tendência de que os comportamentos dos agentes se adequem aos constrangimentos impostos pela estrutura (Elias I993). Conforme se argumentou acima, a estrutura anár-

I6 É importante salientar que pressupor que os sistemas políticos internacionais são ontologicamente anárquicos e que suas unidades possuem capacidade autônoma de escolha não implica a inexistência de relações hierárquicas entre os estados. O que de fato a inexistência de autoridade central implica é que é a distribuição dos meios de força no sistema que define quais unidades sofrerão maiores constrangimentos estruturais ao exercerem suas ações (Gilpin I98I, 28).

I7 Anthony Giddens (200I, 85) argumenta que "os recursos envolvidos na reprodução dos sistemas sociais que têm algum grau de continuidade no espaço e no tempo formam aspectos das propriedades estruturais desses sistemas sociais". Nesse sentido, delimitou-se neste estudo que os sistemas políticos internacionais se referem às interações que envolvem o uso ou ameaça do uso da força entre estados. Por conta disso, o modo como os meios de coerção estão distribuídos também é elemento definidor da estrutura desse tipo de sistema.

ı8 Pressupor que os sistemas políticos internacionais são ontologicamente competitivos não significa excluir a possibilidade de cooperação entre os estados. Implica apenas reconhecer que iniciativas de cooperação serão sempre permeadas pela desconfiança derivada da incerteza informacional em relação às motivações das partes envolvidas, bem como da inexistência de uma autoridade central capaz de assegurar o controle comportamental.

I9 Ressalta-se que a capacidade de se defender militarmente de agressões externas não é o único meio que permite a sobrevivência de um estado nos SPI. De fato, há inúmeros casos de estados que não possuem os meios necessários para resistirem a agressões externas e continuam existindo. No entanto, argumenta-se que tais estados possuem sua capacidade de ação nos SPI extremamente constrangidas. 
quica dos SPI faz com que a natureza da competição internacional envolva a sobrevivência dos estados. Por conta disso, a guerra se torna elemento fundamental da socialização-seleção nos sistemas políticos internacionais, tanto eliminando agentes que não se adaptam às pressões estruturais quanto incentivando a emulação de estratégias percebidas como vencedoras (Levy e Thompson 20II, 61; Posen 1993, 82).

O segundo pressuposto ontológico do modelo de estrutura proposto por Waltz é que há baixa diferenciação funcional nos SPI. De acordo com Buzan e Little (2000), a diferenciação funcional em sistemas sociais ocorre quando as unidades se especializam, assumindo tarefas e objetivos específicos. Nesses casos, os agentes se tornam interdependentes em função da divisão social do trabalho. Tal condição atua como constrangimento para a ação individual, já que a sobrevivência de uma unidade depende não só das suas próprias capacidades, mas também das atividades realizadas pelas demais. Agentes que executam funções similares ${ }^{20}$ dependerão menos uns dos outros e, consequentemente, manterão maior autonomia nos sistemas em que se inserem (Elias I993, 206).

Argumenta-se que níveis distintos de concentração dos meios de coerção implicam diferentes possibilidades de diferenciação funcional. Quanto menor for a concentração, maior será a incerteza comportamental e maior a insegurança. Logo, menores serão os incentivos estruturais para o aumento da divisão de trabalho. Na medida em que a monopolização da força aumenta, a incerteza comportamental diminui, e com ela a insegurança é reduzida. Consequentemente, a divisão de trabalho entre as unidades poderá se intensificar (Waltz I979, I04). Conforme Norbert Elias (1993, I98, grifos nossos):

[...] as sociedades sem um monopólio estável da força são sempre aquelas em que a divisão de funções é relativamente pequena, e relativamente curtas as cadeias de ações que ligam os indivíduos entre si [...]. Ao se formar um monopólio da força, criam-se espaços sociais pacificados, que normalmente estão livres de atos de violência. As pressões que atuam nesses espaços são diferentes das que existiam antes.

Desse modo, discorda-se da afirmação de Hendrick Spruyt de que: “a condição da anarquia implica na existência de um tipo particular de unidade”

20 É importante salientar que este estudo se refere à similaridade funcional entre os estados apenas no âmbito da competição internacional e da concentração dos meios de coerção nos SPN. Ou seja, considera-se como condição necessária para definição dos agentes nos SPI que as organizações políticas sejam capazes de se defenderem de agressões externas e concentrarem os meios de coerção em seus respectivos SPN. No entanto, é evidente que, além dessas duas funções, cada estado pode executar tarefas específicas. 
(Spruyt I994, I3). No âmbito das interações que envolvem a força, quando uma ou algumas poucas organizações políticas monopolizam os meios de coerção e impõem ordens de regulação comportamental às demais a anarquia começa a mudar. No limite, tal mudança alteraria o constrangimento estrutural que induz os agentes a construírem meios de coerção que asseguram sua sobrevivência. Nesse caso, os estados se tornariam "livres para se especializarem, pois não haveria mais razões para temer o crescimento da interdependência que ocorre com a especialização" (Waltz I979, I04, tradução nossa). Estaríamos diante do fim de um sistema composto pela interação entre organizações políticas independentes e da subsequente formação de um sistema político global único.

Portanto, apesar de se concordar com os pressupostos da anarquia e da baixa especialização funcional presentes no modelo waltziano, ele apresenta uma lacuna teórica ao omitir determinadas dinâmicas que atuam nos processos evolutivos dos SPI. De acordo com Waltz, sua definição de estrutura implica necessariamente na emergência do mecanismo da balança de poder (Waltz I979, I2I). Ou seja, segundo ele, enquanto não houver autoridade central única, o comportamento das unidades resultará em uma tendência de restauração da desconcentração dos meios de força no sistema (Waltz I986, 53).

No entanto, argumenta-se que os pressupostos da anarquia e da baixa especialização funcional não implicam necessariamente a existência de apenas um mecanismo, o qual incentivaria sempre a restauração da desconcentração de força no sistema. De fato, verifica-se a emergência de múltiplos mecanismos que fortalecem trajetórias evolutivas distintas e até mesmo conflitantes (Hui 2005, I).

O conceito de mecanismo, por sua vez, é alvo de intensa controvérsia na literatura (Elster I989; Tilly e Goodin 2006; Archer 20I5). No entanto, nota-se que há relativo consenso na concepção de que eles representam as formas pelas quais uma variável produz efeitos em outra (Hedstrom e Ylikoski 20I0). Roy Bhaskar (I998 34,) argumenta que "mecanismos se combinam para gerar o fluxo de fenômenos que constituem os atuais estados e acontecimentos do mundo". Charles Tilly e Richard Goodin (2006, 13) salientam que mecanismos geram transferências de energia entre elementos e rearranjos no posicionamento das unidades. Anna Grzymala-Busse (20II, I268) considera que "a análise de mecanismos e processos envolve temporalidade, na medida que mecanismos especificam mudança: como e por que transformações, tendências e desenvolvimentos ocorrem".

Argumenta-se que as distinções nos sentidos atribuídos ao conceito de mecanismos residem no fato de que sua lógica explicativa depende da on- 
tologia do sistema avaliado. Em sistemas fechados, nos quais as interações com o ambiente e o número de elementos podem ser controladas, mecanismos descrevem relações funcionais entre pares de variáveis. Ou seja, a trajetória de eventos que se inicia com alterações em determinada variável independente e gera modificações em uma variável dependente (Vasconcellos 20I3, 8I). Nesse caso, a trajetória de evolução do sistema tenderá a ser linear, pois a soma das ações individuais é igual ao comportamento agregado (Mitchell 2009, 22).

Por sua vez, em sistemas abertos, nos quais as influências de variáveis exógenas e o número de interações entre as unidades é alto ${ }^{21}$, mecanismos não operam da mesma maneira (Bhaskar I998). Em função da interconexão entre os agentes, é impossível agir isoladamente nesse tipo de sistema (Hardin I963). Por conta disso, pequenas modificações em um ponto específico podem desencadear desproporcionais e/ou inesperadas consequências em seu estado geral (Elster I989). Logo: “organizações podem não compreender as implicações do que elas estão fazendo, e pode-se levar um longo tempo para que as consequências de suas ações emerjam completamente" (Levy e Thompson 20II, II, tradução nossa). Ademais, as relações causais entre seus componentes poderão ser recursivas (Jaccard e Jacoby 2009). Ou seja, embora uma determinada entidade $\mathrm{X}$ exerça efeito em outra entidade $\mathrm{Y}$, nada impede que em um segundo momento $Y$ também exerça efeito sobre $X$.

Assim, a trajetória de evolução de sistemas abertos não é linear. Dado que "uma mudança continuada no valor de uma variável pode gerar um comportamento descontinuado no sistema inteiro" (Wimmer 2006, 8, tradução nossa), transformações podem ocorrer tanto gradualmente quanto de maneira abrupta. Em tais contextos, atuam tanto mecanismos que reforçam tendências de mudança (mecanismos de feedback positivo), quanto mecanismos que operam na restauração do estado inicial (mecanismos de feedback negativo), conforme Thelen (2003) e Hui (2005).

Por fim, em função das interações com o ambiente externo, as modificações no sistema são irreversíveis (Prigogine e Stengers 1984). Em outras palavras, a dinâmica sistêmica depende não apenas de alterações em variáveis, mas também da trajetória temporal específica em que essas mudanças ocorreram (Pierson 2004). Logo, não apenas ações semelhantes podem produzir efeitos distintos dependendo do momento em que ocorrerem, mas também, escolhas em determinado período constrangem as possibilidades de vias alternativas no futuro (Thelen 2003).

2I O número de elementos importa, pois na medida em que ele se expande torna-se cada vez mais complicada a identificação de variáveis exclusivamente independentes, bem como a mensuração dos efeitos (Pierson 2004). 
Sistemas políticos internacionais são sistemas sociais abertos e compostos pelas interações entre um número significativo de unidades. Portanto, seus processos evolutivos são necessariamente imprevisíveis e resultantes das interações estratégicas entre agentes, variáveis exógenas e mecanismos concorrentes (Hedstrom e Ylikoski 20ı০, 60). Em outras palavras, interações que envolvem o uso ou ameaça do uso da força entre os estados não implicam necessariamente na desconcentração dos meios de força no sistema e, de fato, há múltiplas trajetórias de evolução possíveis para os SPI.

Nesse sentido, pode-se resumir a relação entre agentes e estrutura nos SPI nas seguintes etapas: em um primeiro momento ${ }^{22}$, a competição internacional em uma estrutura anárquica constrange a variabilidade comportamental dos estados. Tais pressões incentivam as unidades a buscarem meios que lhes assegurem a sobrevivência, porém são assimiladas e respondidas de acordo com as características específicas de cada agente. Em um segundo momento, das interações entre as estratégias escolhidas por cada estado para enfrentar a competição internacional emergem mecanismos transformacionais $^{23}$ que produzem efeitos sobre o nível estrutural. Geram-se tendências tanto em direção à descentralização dos meios de força quanto para sua concentração (Braumoller 20I2).

Logo, na medida em que "a contingência e o fluxo do mundo social, em que múltiplos mecanismos estão em constante interação, mecanismos não podem ser determinísticos" (Wight 20I5, 52, tradução nossa). Neste sentido, a inconsistência do modelo waltziano consiste na omissão de mecanismos que poderiam superar a tendência ao balanceamento ${ }^{24}$. Logo, a questão é saber em que condições a competição internacional engendra mecanismos que reforçam processos de concentração dos meios coercitivos nos sistemas políticos internacionais.

Victoria Tin-bor Hui (2005) avançou nesse sentido ao analisar o processo de transformação do SPI formado por reinos soberanos na China antiga, para um sistema político nacional unificado no Império da dinastia Qin

22 Iniciar a análise pelos efeitos da estrutura sobre as unidades não significa atribuir precedência temporal a eles. Conforme se argumentou na primeira parte deste trabalho, para discernir os efeitos nas relações entre agente e estrutura, é preciso considerar a trajetória temporal em que eles ocorrem (Friedman e Starr I997). Assim, poder-se-ia ter começado avaliando os efeitos das unidades sobre a estrutura sem que houvesse prejuízo analítico.

23 De acordo com Hedstrom e Ylikoski (20I0, 59), mecanismos situacionais são aqueles pelos quais as estruturas sociais constrangem as ações individuais. Por sua vez, mecanismos transformacionais são aqueles pelos quais os indivíduos, por meio de suas ações e interações, geram diversos resultados intencionais e não intencionais e alteram a estrutura.

24 De fato, apesar de não desenvolver a argumentação, Waltz sugere em determinados momentos a possiblidade de superação da lógica da anarquia pelos agentes dos SPI. 
durante o período 656-22I a.C. ${ }^{25}$. A autora parte do pressuposto de que aquele SPI era caracterizado pela anarquia e por intensa competição entre suas unidades (Hui 2005, 5). Esse diagnóstico vai ao encontro da análise de Kiser e Cai (2003, 519), que consideram que: "houve apenas 38 anos pacíficos entre $772-485$ a.C, e apenas 89 entre 463-222 a.C”. Contudo, com a expansão do Reino Qin, a estrutura anárquica do sistema não engendrou mecanismos que impedissem a concentração dos meios de força.

Hui (2005) argumenta que inicialmente o sistema político internacional chinês evoluiu de acordo com os pressupostos do modelo waltziano. Isto é, a competição internacional e o mecanismo da socialização homogeneizaram os comportamentos dos agentes. Assim, não só as organizações políticas se tornaram militarizadas, como também realizavam guerras, formavam alianças e estabeleciam contatos diplomáticos em períodos de paz. Além disso, no período de 656 a.C. até 284 a.C., alianças de balanceamento e o aumento nos custos de projeção de força ${ }^{26}$ sustentaram a estrutura anárquica. Ou seja, todos os estados que tentaram dominar a agência das demais unidades nesse período "pereceram como resultado do mecanismo da balança de poder e do aumento nos custos de expansão" (Hui 2005, tradução nossa).

Entretanto, ainda que a estrutura do SPI tenha induzido a adoção de comportamentos similares por parte das unidades, cada reino optou por estratégias distintas para enfrentar a competição internacional. Segundo a autora, o Reino Qin teria respondido por meio de reformas administrativas internas que lhe asseguraram vantagens relativas em relação aos seus competidores. Victoria Tin-bor Hui denominou esse tipo de ação como reforma fortalecedora: "esforços para aumentar as capacidades econômicas e militares por meio do incremento da capacidade administrativa estatal" (Hui 2005, 79). Três dimensões são fundamentais para o sucesso dessa estratégia: o estabelecimento de exércitos nacionais conscritos, a burocratização dos quadros administrativos e a imposição de um sistema tributário centralizado. O quadro I sintetiza as características de cada dimensão, bem como seus efeitos do ponto de vista externo e interno nas capacidades dos estados:

25 A obra de Hui (2005) será analisada, pois a autora utiliza o modelo de sistema político internacional de Kenneth Waltz como pressuposto teórico. No entanto, é importante salientar que há consistente agenda de pesquisa sobre a influência da guerra no processo de expansão do reino Qin. Ver: Mann (1986), Wong (1997), Kiser e Cai (2003), Lewis (2006; 2007).

260 aumento nos custos de projeção de força se refere ao fato de que se torna muito custoso economicamente ao estado sustentar os recursos materiais e humanos necessários para garantir a dominação em lugares afastados de sua base (Gilpin I98I, I03). É com base nessa constatação que se concebe o conceito de perda do gradiente de força, que indica o aumento nas dificuldades de se projetar poder militar em regiões geograficamente distantes da base do estado, principalmente através de grandes massas de água (Boulding I962; Mearsheimer 200I). 


\section{Quadro 1:Reformas Fortalecedoras: Competição Internacional e Formação do Estado}

\begin{tabular}{|c|c|c|}
\hline Reforma Fortalecedora & Competição Internacional & Formação do Estado \\
\hline $\begin{array}{c}\text { Exércitos nacionais } \\
\text { conscritos e permanentes. }\end{array}$ & $\begin{array}{c}\text { Aumento do número de } \\
\text { combatentes e } \\
\text { da efetividade em } \\
\text { combate. }\end{array}$ & $\begin{array}{c}\text { Monopolização dos meios } \\
\text { de coerção e } \\
\text { criação de apara- } \\
\text { to administrativo. }\end{array}$ \\
\hline $\begin{array}{r}\text { Burocratização: critérios } \\
\text { meritocráticos } \\
\text { para formação } \\
\text { dos quadros ad- } \\
\text { ministrativos. }\end{array}$ & $\begin{array}{c}\text { Mobilização de recursos e } \\
\text { controle de terri- } \\
\text { tórios conquista- } \\
\text { dos. }\end{array}$ & $\begin{array}{l}\text { Aumenta capacidade } \\
\text { administrativa e } \\
\text { facilita o controle } \\
\text { comportamental. }\end{array}$ \\
\hline $\begin{array}{l}\text { Sistema tributário } \\
\text { centralizado. }\end{array}$ & $\begin{array}{c}\text { Maiores e mais confiáveis } \\
\text { fontes de finan- } \\
\text { ciamento para as } \\
\text { guerras. }\end{array}$ & $\begin{array}{c}\text { Mais recursos para } \\
\text { dominação } \\
\text { interna. Diminui } \\
\text { a influência } \\
\text { de outras } \\
\text { organizações e } \\
\text { atores privados. }\end{array}$ \\
\hline
\end{tabular}

O início das reformas fortalecedoras no Reino Qin ocorre com chegada ao poder do primeiro ministro Shang Yang, em meados de 359 a.C. (Kiser e Cai 2003) $)^{27}$. Aproveitando-se de inovações tecnológicas nos equipamentos militares ${ }^{28}$, Yang estabeleceu a conscrição em larga escala nos territórios controlados por Qin (Lewis 2007, 3I 2 $^{29}$. A partir de então, todos os homens entre I5 e 60 anos poderiam ser recrutados para combater (Kiser e Cai 2003, 520). Nesse contexto, as forças combatentes do reino passaram a ser compostas não apenas pela cavalaria montada em carruagens - formada por combatentes originários da aristocracia agrária — mas também por infantarias constituídas por massas de soldados camponeses (Hui 2005, 80). Além disso, instaurou-se sistemas de punições e incentivos por covardia ou bravura em combate: "qualquer um que tivesse mérito em matar inimigos no campo de batalha ou comandar unidades vitoriosas era promovido" (Lewis 2007, 32).

27 Shang Yang havia anteriormente servido no reino Wei, onde também introduziu reformas fortalecedoras em menor escala. Sua importância na implementação das reformas no Reino Qin sugere a relevância da difusão da inovação tecnológica como mecanismo que intermedeia os efeitos da competição internacional sobre os agentes.

28 Entre as inovações tecnológicas que contribuíram para a massificação dos exércitos estão a invenção da besta e o desenvolvimento de espadas e lanças mais baratas feitas de bronze.

29 Apesar das dificuldades em relação à obtenção de dados confiáveis para esse período, Kiser e Cai $(2003)$ estimam que o contingente total do exército Qin alcançaria entre 500 mil soldados. 
Esse modelo se tornou "a forma mais importante de ascensão durante essa era", já que "o mérito militar se tornou mais importante do que uma linhagem nobre” (Hsu I965, 73, apud Kiser e Cai 2003, 521). Ademais, a formação de exércitos cada vez maiores induziu à construção de instituições capazes de gerenciar os imperativos logísticos necessários para sustentar tal projeção de força (Lewis I990, 9). Portanto, nota-se que não só as capacidades de Qin aumentavam em relação aos demais estados do SPI, mas também que o estado se fortalecia vis a vis os detentores de poder privados (Kiser e Cai 2003, 520).

A burocratização da administração, ao diminuir a influência das elites agrárias, foi outro elemento que contribuiu para o aumento da capacidade de intervenção do estado no sistema político nacional. Gradualmente, no lugar da nobreza, o estado foi dominado por um único governante autocrático, cujos agentes registravam e mobilizavam os camponeses para o serviço estatal, bem como coletavam os impostos que sustentavam a expansão militar (Lewis 2007, 32). O território foi dividido em 36 distritos administrativos que eram idênticos às unidades de recrutamento militar e que foram repartidos em subunidades controladas por funcionários indicados pelo soberano (Rosenstein 2009). Nesses distritos, as nomeações de oficiais por mérito aumentaram em relação às alcançadas por hereditariedade. Ademais, códigos com as leis do estado central começaram a ser publicados em todas as regiões do reino e funcionários públicos foram obrigados a enviar detalhados relatórios anuais sobre as condições de cada localidade.

Objetivando diminuir os custos relacionados ao controle comportamental dos demais agentes do SPN, a população foi dividida em grupos formados por io famílias no máximo. Caso um indivíduo cometesse alguma transgressão, o grupo inteiro ao qual ele pertencia era responsabilizado. No entanto, se o criminoso fosse denunciado às autoridades, o grupo receberia benefícios em terras e cargos oficiais. Segundo Kiser e Cai $(2003,528)$, a vantagem de tal forma de controle era que "[e]sse tipo de mecanismo de controle social coloca todos em constante supervisão local e, portanto, tornava a coleta de impostos e o recrutamento militar muito mais fácil".

Em relação à mobilização de recursos, nota-se que a atividade agrícola era percebida como essencial para a sustentação de forças militares (Lewis 2007). Desse modo, enquanto os setores comerciais e artesanais sofriam penalidades, a agricultura em pequenas propriedades recebia incentivos estatais. Os canais de irrigação e estradas criados nessa época objetivavam tanto escoar de maneira mais eficiente a produção, como aumentar a mobilidade militar (Hui 2005, I72). Além disso, de acordo com Rosenstein (2009, 26), promoveu-se uma rigorosa redistribuição de terras que objetivava, em troca do reconhecimento da propriedade da terra, que os camponeses aquiesces- 
sem ao pagamento de impostos e à prestação de serviço militar. Por sua vez, o aumento populacional foi perseguido por meio de subsídios concedidos para casais com mais de dois filhos e incentivos à entrada de imigrantes. Desse modo, não só a população de Qin aumentava em termos absolutos, mas também em relação aos demais reinos. Nesse contexto, "com a capacidade de mobilizar totalmente os recursos nacionais, o poder e a riqueza de Qin alcançaram o auge" (Hui 2005, 84).

O incremento de suas capacidades materiais em relação aos seus competidores habilitou ações externas mais agressivas $3^{\circ}$ por parte do Reino Qin. Victoria Tin-bor Hui argumenta que, por contar com um corpo burocrático formado de maneira meritocrática, Qin desenvolveu estratégias que exploraram os problemas de ação coletiva ${ }^{3 \mathrm{I}}$ inerentes às alianças balanceadoras eventualmente articuladas contra si (Hui 2005, I00). Assim, enquanto no período de 656-357 a.C. o reino iniciou apenas $7 \%$ das guerras envolvendo os maiores estados do sistema, entre $356-22$ I a.C. ele iniciou $54 \%$ e venceu $92 \%$. Desse total, apenas oito das cinquenta e duas guerras travadas pelo reino encontraram resistência na forma de alianças (Hui 2005, 78). Além disso, "as alianças contra Qin se formavam lentamente, não possuíam atores suficientes para contrapor o reino, raramente tinham comando unificado e rapidamente se desintegravam" (Hui 2005, 79). Por conta disso, em 293 a.C. Qin já havia derrotado as principais forças de seus vizinhos próximos: os reinos de Wei, Han e Chu. Por volta de 257 a.C., o reino controlava cerca de metade do território do sistema. Em 236 a.C., lançou uma guerra final de unificação contra o estado Qi. Consagrando-se vencedor desse conflito, a concentração da força no sistema estava completa sob o comando da Dinastia Qin em 22I a.C. (Hui 2005, 64-79).

Pode-se questionar o porquê do mecanismo da socialização não ter incentivado a emulação das reformas e estratégias perseguidas pelo Reino Qin por parte das organizações políticas rivais. A autora sugere que a trajetória específica de eventos tornou a acumulação de poder um processo de reforço positivo ${ }^{32}$. Em primeiro lugar, a posição periférica de Qin fez com

30 Para análise da relação entre aumento do poder do estado na esfera interna e políticas externas mais agressivas, ver Zakaria (I998).

3І Conforme salienta Mearsheimer (200I), “Formar coalizões balanceadoras rapidamente e colocá-las em funcionamento é sempre difícil, pois leva tempo para se coordenarem os esforços de aliados prospectivos ou estados membros, mesmo quando há amplo acordo sobre o que deve ser feito. Estados ameaçados usualmente discordam sobre como as responsabilidades devem ser distribuídas entre os membros da aliança. Afinal, estados são atores egoístas, com poderosos incentivos para minimizar os custos pagos na contenção de um agressor".

32 De acordo com Hardin (I963, 7I) "poder social é um processo de reforço positivo. Por meio de inúmeros estratagemas um monopolista pode tentar manipular o maquinário da sociedade 
que sua expansão inicial parecesse pouco ameaçadora em relação às múltiplas ameaças com que cada reino se deparava33. Em segundo lugar, após Qin conquistar mais da metade do sistema, "mesmo as capacidades combinadas de todos os seis estados não eram capazes de alcançar a do reino Qin” (Hui 2005, 77). Desse modo, difundiu-se entre os demais reinos a percepção de que o comportamento mais adequado para garantir a sobrevivência não seria a resistência, mas sim a submissão ao estado mais forte ${ }^{34}$.

Vale resumir a evolução da relação agente-estrutura no processo de expansão do Reino Qin, segundo o modelo proposto por Victoria Tin Bor-Hui. Em um primeiro momento, a estrutura anárquica do sistema $(\mathrm{E})$ induziu à competição e incentivou comportamentos similares entre suas unidades. Em seguida, a combinação entre variáveis exógenas (inovação e difusão tecnológica) com respostas de um agente específico (reformas fortalecedoras) alteraram a distribuição de capacidades no sistema e tornaram a conquista e a administração dos territórios dominados menos custosa. Por fim, as interações, exemplificadas pelo embate entre as estratégias antibalanceamento com a resistência coletiva desorganizada dos demais reinos, favoreceram a tendência de concentração de força e resultaram no aumento da especialização funcional do sistema (E'). Logo, ocorreu a transformação de um sistema político internacional em um sistema político nacional.

Concluindo, a obra de Hui sugere que a conjunção entre transformações tecnológicas, reformas fortalecedoras e estratégias de desestabilização de alianças podem superar o mecanismo da balança de poder e tornar a concentração dos meios de coerção um processo de reforço positivo. Logo, a continuidade da existência do SPI formado pelos reinos chineses não estava assegurada, mas sim era dependente de contingências históricas derivadas das interações estratégicas entre os agentes e da influência de variáveis contextuais. Na seção seguinte, avalia-se a ontologia e a evolução dos sistemas políticos nacionais e dos estados. Nesse caso, não apenas a competição internacional importa, mas também as interaç É importante salientar que nem mesmo os governantes do reino Qin inicialmente visavam à dominação do sistema. De acordo com a autora, somente em 287 a.C. houve a primeira

de modo a eliminar as ameaças que objetivam reestabelecer um equilíbrio natural. A história demonstra que um monopolista em uma área tentará estender seu poder para outras, sem limites".

33 É importante salientar que nem mesmo os governantes do reino Qin inicialmente visavam à dominação do sistema. De acordo com a autora, somente em 287 a.C. houve a primeira menção de tal objetivo em documentos de estratégia militar (Hui 2005, I00).

34 Sobre a relação entre percepção de ameaça e incapacidade de formação de alianças de balanceamento, ver Schweller (2004). 
menção de tal objetivo em documentos de estratégia militar (Hui 2005, I00). ões entre estados, organizações não estatais e indivíduos pertencentes aos diferentes SPN.

\section{Sistemas Políticos Nacionais: construção do estado e concorrência regulada}

Sistemas políticos nacionais são constituídos por organizações políticas que centralizam os meios coercitivos e permitem o avanço da divisão do trabalho entre os demais agentes. No entanto, como ocorre nos sistemas políticos internacionais, não há uma lei de ferro que assegure a continuidade dessa estrutura. Assim, não apenas a existência dos SPI, mas também a sobrevivência dos estados e a continuidade dos SPN são fenômenos contingentes.

Primeiramente é necessário diferenciar os estados das demais unidades dos sistemas políticos nacionais. De acordo com Charles Tilly (I993, 46), estados são “organizações que aplicam coerção, distintas das famílias e dos grupos de parentesco e que em alguns aspectos exercem prioridade manifesta sobre todas as outras organizações dentro de extensos territórios". Por sua vez, Stein (2008, I29) compreende que organizações são "entidades conceitualmente reconhecidas que combinam grupos de pessoas com regras comuns definidas". Logo, estados constituem apenas um dos agentes que formam o SPN, o qual também é composto por organizações não estatais e por indivíduos. Sua especificidade reside em sua reivindicação do monopólio do uso legítimo dos meios de força no território delimitado (Weber 1999).

Processos de formação de estados ocorrem quando organizações monopolizam os meios de coerção em um sistema social (Tilly I996). Tais empreitadas enfrentam a oposição de organizações políticas rivais internamente, bem como ameaças de outras unidades pertencentes aos SPI. Assim, para se consolidarem, estados precisam desenvolver meios que lhes permitam extrair e converter os recursos produzidos no sistema político nacional em capacidades materiais para o enfrentamento da resistência doméstica e da competição internacional (Giddens 200I).

Desse modo, nota-se que estados não se formam por meio de acordos entre o soberano e a sociedade, como sugerem abordagens contratualistas ${ }^{35}$,

35 Por contratualismo, entende-se: "todas aquelas teorias políticas que veem a origem da sociedade e o fundamento do poder político num contrato, isto é, num acordo tácito ou expresso entre a maioria dos indivíduos, acordo que assinalaria o fim do estado natural e o início do estado social e político" (Matteucci I998, 272). Para avaliação de abordagens contratualistas 
mas sim resultam dos esforços de monopolização dos meios coercitivos por parte de uma organização em detrimento de outras. Logo, processos de formação de estados envolvem necessariamente conflitos de interesses entre organizações políticas e os demais componentes dos SPN. De fato, Tilly (I985) argumenta que, antes de proverem segurança, eles seriam a principal ameaça potencial aos indivíduos e organizações não estatais.

$\mathrm{Na}$ seção anterior argumentou-se que a insegurança e a baixa especialização funcional entre as unidades predominavam nos SPI em função da anarquia. Por sua vez, salientou-se agora que estados concentram os meios de coerção nos sistemas políticos nacionais. A diferença na distribuição dos meios coercitivos em cada sistema possui implicações nos mecanismos que atuam em seus respectivos processos evolutivos. Em outras palavras, a competição entre os agentes dos SPN está sujeita às pressões derivadas de uma estrutura distinta daquela encontrada no SPI.

Resulta dessa distinção que, enquanto no SPI a ação das unidades é constrangida pela insegurança derivada da incerteza acerca das intenções das demais unidades, nos SPN a variação comportamental é delimitada por uma ordem reguladora imposta pela organização estatal. Max Weber define ordem reguladora como o conjunto de regras "que regula outras ações sociais e garante por meio desta regulação as probabilidades facultadas aos agentes" (Weber 20I0, 99). Por conta disso, nos SPN diminui-se a insegurança individual na medida em que a ordem restringe os meios tolerados nas interações competitivas entre as unidades.

Nota-se que a competição e o mecanismo da socialização não são eliminados, mas operam de maneira distinta. Argumenta-se que a diferença fundamental é que, em um sistema no qual há uma ordem reguladora imposta pelo estado, a sobrevivência dos agentes não depende de suas próprias capacidades. Consequentemente, nesses sistemas os incentivos e constrangimentos derivados da estrutura possibilitam o aumento da especialização funcional entre as unidades (Elias I993).

Segundo Waltz (1986, 324), o incremento da especialização funcional ocorre quando aumenta a divisão de trabalho entre as unidades do sistema. Não mais preocupados com ameaças físicas, os agentes podem deixar de buscar meios coercitivos e executar atividades específicas que se insiram no funcionamento da coletividade. Logo, se o SPI se caracteriza pela similaridade funcional entre unidades soberanas, os agentes dos SPN estariam integrados pela divisão social do trabalho que os torna interdependentes entre si (Doyle I986).

sobre processos de formação do estado, ver Moore (2008). 
Assim, o aumento da especialização funcional é inextrincável da formação de organizações políticas que concentrem meios coercitivos e assegurem ordens de regulação comportamental. Ou seja, somente quando "criam-se espaços sociais pacificados [é que] as pressões que atuam sobre as pessoas nesses espaços são diferentes das que existiam antes" (Elias I993, I98). Nesses espaços, a socialização constrange os agentes a reprimirem impulsos de agressão física. Por conta disso, a natureza da competição se diferencia, não estando mais em jogo a sobrevivência da unidade, mas sim seu posicionamento em uma rede ampla e integrada de interações (Elias I993, I32).

Contudo, argumenta-se que o aumento da especialização funcional em um sistema político nacional não implica a eliminação dos conflitos de interesse entre suas unidades. Logo, qual a natureza da competição em um sistema no qual há uma ordem reguladora imposta pela organização estatal? Recorre-se à distinção proposta por Max Weber entre os conceitos de poder e dominação ${ }^{36}$ para avançar nessa questão. Segundo Weber: "poder significa toda a probabilidade de, dentro de uma relação social, impor a vontade própria mesmo contra a resistência, seja qual for o fundamento dessa probabilidade" (Weber 20IO, I02). Por sua vez, "dominação denominar-se-á a probabilidade de encontrar obediência a uma ordem de determinado conteúdo em dadas pessoas" (Weber 2010, I02).

Em função da inexistência de uma autoridade central, nos SPI predominam relações de poder. Ou seja, não há regulação forte dos meios pelos quais uma organização política tenta ${ }^{37}$ impor sua vontade sobre as outras ${ }^{38}$. Por sua vez, definiu-se que os estados concentram os meios de coerção e estabelecem ordens reguladoras sobre o comportamento dos demais agentes dos SPN. Assim, nesse tipo de sistema a obediência aos limites comportamentais delimitados se configura como uma relação de dominação e autoridade entre governantes e os governados.

36 Sobre o conceito de poder, ver Dahl (I96I) Giddens (200I) e Lukes (2004). Recorre-se à definição weberiana para salientar a distinção entre sistemas sociais nos quais não há regulação superior acerca dos meios pelos quais um agente pode impor sua vontade sobre outro, de sistemas sociais nos quais há uma ordem reguladora delimitando os comportamentos aceitáveis pelas unidades.

37 Destaca-se a importância do termo tentar, pois, conforme salienta Giddens (200I, 36), "um agente pode estar em uma posição de poder no sentido de que tenha capacidade de empregar uma gama de recursos. Mas até onde esses recursos podem ser usados para assegurar resultados específicos depende da garantia de quaisquer consentimentos que forem necessários da parte de outros agentes".

38 Conforme se argumentou anteriormente, tal configuração não implica aleatoriedade de resultados ou mesmo caos, mas sim padrões de comportamento que emergem de maneira descentralizada a partir de expectativas comportamentais derivadas da distribuição de força no sistema. 
Weber argumenta que uma ordem reguladora "existe quando há uma probabilidade de que ela será mantida por um quadro específico de pessoas que se utilizarão da compulsão física com a intenção de obter conformidade em relação à ordem ou de aplicar sanções a sua violação" (Weber i98I, 6I) Ou seja, na medida em que: "para o cumprimento mesmo de uma pauta 'mínima' o Estado não pode evitar completamente interferir na vida econômica da coletividade que o sustenta" (Reis 2003, 65), sua consolidação exige não só a concentração de meios de força, mas também a criação de instituições administrativas, necessárias para a intervenção na sociedade (Bendix I976, 23) 39.

Ou seja, embora a posse de meios coercitivos seja condição necessária para a imposição da ordem reguladora, a dominação estatal se torna insustentável se fundamentada apenas na coerção (Buzan i984, 53). Conforme argumenta Wong (1997, 74): "controle coercitivo é caro, intensivo em trabalho e muitas vezes intensivo em capital". Portanto, ainda que a concentração dos meios de força seja fundamental para a regulação comportamental, estados são incapazes de se sustentarem sem a aquiescência de outras organizações dentro da sociedade ${ }^{40}$. Desse modo, "a questão da legitimidade torna-se fundamental, já que apenas ela seria a garantia última da subsistência de uma associação política" (Bianchi 20I4, IOO)4 ${ }^{4}$. Assim, os agentes estatais se esforçariam para consolidar as relações de dominação por meio de "atos de persuasão, como a criação em credos de moralidade, sensibilidade, necessidade ou o desejo por uma determinada ordem social" (Wong 1997, 74). Em outras palavras:

Se o Estado pode contar com a adesão da população às normas vigentes, de maneira não só a cumpri-las rotineiramente, mas também a punir os recalcitrantes - ou ao menos denunciá-los às autoridades competentes -, então é lícito esperar um desempenho mais eficiente das instituições políticas (Reis 2003, 63).

39 De acordo com Max Weber (I99I, 96): “O desenvolvimento qualitativo e quantitativo das tarefas administrativas favorece, a longo prazo, inevitavelmente, a continuidade efetiva de pelo menos uma parte dos funcionários, porque a superioridade técnica na administração dos assuntos públicos fundamenta-se de maneira mais sensível, em treinamento e experiência. Por isso, há sempre a probabilidade de que se constitua uma formação social especial e perene para os fins administrativos, e isto significa ao mesmo tempo: para o exercício da dominação". 40 Conforme salienta Miguel Centeno (2002, I06): “a capacidade de o estado extrair recursos estará relacionada intimamente com a disposição da população aceitar esse fardo".

4I Define-se legitimidade como: "um atributo do Estado, que consiste na presença, em uma parcela significativa da população, de um grau de consenso capaz de assegurar a obediência sem a necessidade de recorrer ao uso da força, a não ser em casos esporádicos. É por esta razão que todo poder busca alcançar consenso, de maneira que seja reconhecido como legítimo, transformando a obediência em adesão" (Levi I998, 675). 
Isto é, "estados precisam de uma base física de população e território; precisam de instituições de governança que controlem a base física e precisam de uma ideia de estado que estabeleça a autoridade na mente da sua população" (Buzan I984, 40). Em resumo, a dominação estatal sobre os demais componentes dos SPN é sustentada pela concentração dos meios coercitivos e pela legitimidade da ordem reguladora.

Porém, ainda é necessário explicar como a concentração dos meios de força, o estabelecimento de uma ordem reguladora, e a própria especialização funcional condicionam as interações entre indivíduos e organizações não estatais.

Argumentou-se que a sobrevivência das unidades (organizações e indivíduos) está razoavelmente garantida nas interações que ocorrem dentro de sistemas políticos nacionais em que há monopólio estatal dos meios coercitivos e uma ordem reguladora ${ }^{42}$. Todavia, conflitos de interesses não ocorrem exclusivamente por meio da coerção. De fato: "há um conjunto inteiro de meios cuja monopolização permite ao homem, como grupo ou indivíduo, impor sua vontade aos demais" (Elias I993, I46)43. Desse modo, nos SPN “os grupos cuja existência social é mutualmente dependente, através da divisão das funções, ainda lutam por certas oportunidades. Eles são, simultaneamente, adversários e parceiros" (Elias I993, I47). Logo, conforme salienta Lockwood (1956, 139), o aumento da divisão do trabalho que resulta da pacificação é também causa de novos conflitos de interesses.

Nesse caso, Weber argumenta que a competição ocorre em torno das oportunidades específicas de vida, decorrentes do posicionamento das unidades na estrutura de distribuição das ordens econômicas e sociais (Weber I98I, 62-63) $)^{44}$. O autor denominou tal tipo de competição como concorrência

42 É importante salientar que o uso da coerção não se restringe ao âmbito internacional. A distinção relevante para este artigo é que nos sistemas políticos nacionais, com exceção das organizações estatais, os agentes não se organizam coletivamente para ameaçar ou utilizar a força física para defender seus interesses. Quando o fazem, estão sujeitos às penalidades definidas na ordem reguladora e impostas pela organização estatal.

43 Conforme argumenta Pasquino (I998, 226), "a violência pode ser considerada um instrumento utilizável num conflito social ou político, mas não o único e nem necessariamente o mais eficaz".

44 De acordo com Weber (I981, 63): “podemos denominar de 'ordem social' a forma pela qual a honra social se distribui numa comunidade entre grupos típicos participantes dessa distribuição. A ordem social e a ordem econômica estão ambas, é evidente, relacionadas com a 'ordem legal'. Entretanto, a ordem social e a econômica não são idênticas. A ordem econômica é para nós apenas a forma pela qual os bens e serviços econômicos estão distribuídos. A ordem social é, obviamente, condicionada em alto grau pela ordem econômica, e por sua vez reage a ela". 
regulada: "na medida em que está orientada, nos fins e nos meios, por uma ordem" (Weber 20ıо, 72). Ou seja, ainda que haja regulação dos meios tolerados na competição social, a posição do agente na divisão do trabalho fornecerá maior - ou menor - acesso aos recursos necessários para a defesa de seus interesses no SPN (Hay e Wincott I998, 956)45. Portanto, embora os meios utilizados da concorrência regulada sejam variáveis, considera-se que:

Os processos de constituição da sociedade são, muitíssimas vezes, simplesmente compromissos de interesses antagónicos, os quais neutralizam apenas uma parte do objecto ou dos meios de luta, mas deixam, de resto, subsistir a oposição de interesses e a concorrência em torno das probabilidades. E o ordenamento da acção social, seja qual for a sua espécie, deixa, como se afirmou, subsistir de qualquer modo a pura selecção efectiva na competição dos diferentes tipos humanos em torno das probabilidades da vida (Weber 2010, 80).

Evidenciam-se, pois, três dimensões distintas de conflito envolvendo os estados: a competição internacional, decorrente da insegurança comportamental derivada da estrutura anárquica dos SPI; a construção do estado em si mesma, eivada de tensão entre estado e as demais organizações e indivíduos dos SPN (sobretudo a respeito da extração dos recursos para a defesa externa, monopolização da coerção interna e imposição da ordem reguladora); e a concorrência regulada, representada pelos conflitos de interesses entre organizações não estatais e indivíduos em torno da distribuição dos meios permitem acesso às oportunidades específicas de vida (Quadro 2).

\section{Quadro 2: Dimensões do Conflito envolvendo os Agentes do SPI e dos SPNs}

\begin{tabular}{|c|c|c|}
\hline Tipos de Conflito & Agentes & Meios \\
\hline Competição Internacional & Estados pertencentes ao SPI & $\begin{array}{r}\text { Capacidades materiais } \\
\text { para a guerra }\end{array}$ \\
\hline Construção do Estado & $\begin{array}{r}\text { Estado, organizações e } \\
\text { indivíduos perten- } \\
\text { centes ao SPN }\end{array}$ & $\begin{array}{r}\text { Coerção e formação de } \\
\text { legitimidade }\end{array}$ \\
\hline
\end{tabular}

45 De acordo com Elias (I993, I05): "graças à centralização e à monopolização, oportunidades que antes tinham que ser conquistadas por indivíduos com emprego de força militar ou econômica tornam-se passíveis de planejamento. A partir de certo ponto do desenvolvimento, a luta pelos monopólios não visa mais à sua destruição. É uma luta pelo controle do que eles produzem, por um plano de acordo com o qual seu ônus e benefícios sejam mais divididos, numa palavra, pelas chaves para a distribuição". 


\begin{tabular}{|l|c|r|}
\hline Concorrência Regulada & $\begin{array}{c}\text { Organizações não estatais e } \\
\text { indivíduos }\end{array}$ & $\begin{array}{r}\text { Delimitados pela ordem } \\
\text { reguladora im- } \\
\text { posta pelo Estado }\end{array}$ \\
\hline Fonte: Elaborado pelos autores.
\end{tabular}

Os três tipos de conflitos estão vinculados. Note-se, por exemplo, que a ordem reguladora imposta pelo estado não é neutra em relação à concorrência regulada. Ou seja, "a estrutura de toda ordem legal influencia diretamente a distribuição de poder, econômico ou de outra natureza” (Weber I98I, 6I). Assim, os benefícios provenientes da ordem sustentada pelos estados tendem a ser direcionados para os agentes que dominam e lhes fornecem os recursos necessários para suas finalidades (Mann I992, I3). Tal condição se explicita fundamentalmente na tributação, cuja estipulação é resultado de pressões e contrapressões políticas (Reis 2003, 65).

Logo, a existência de uma ordem reguladora implica na continuidade de conflitos de interesse no sistema, dado que "a imposição da ordem necessariamente resolve o conflito em termos favoráveis a uma ou outra parte" (Clarke i99I, 4). Assim, a natureza da ordem imposta pelo estado é objeto de disputa pelos demais agentes, na medida em que ela define as expectativas comportamentais da competição entre eles (Lustick 20II, 2). Isto é, embora os estados estabeleçam relações de dominação sobre os indivíduos e organizações não estatais, eles também são condição necessária para o aumento da divisão do trabalho que permite a própria integração dos SPN. Todavia, a ordem que sustenta o incremento da especialização funcional não é neutra, favorecendo os interesses de determinados agentes em troca da aquiescência e apoio à dominação estatal (Elias, I993). No limite, são tais assimetrias e vieses que alimentam as revoluções e/ou as reformas nos sistemas políticos nacionais ao longo do tempo (Cepik I999).

Ademais, a dominação estatal é contextualmente variável (Stein 2008, I64). Na medida em que os governantes concentrarem legitimamente os recursos necessários para sobreviverem no SPI e monopolizarem os meios de coerção no SPN, eles terão não só maior liberdade de ação externa, mas também maior autonomia em relação às demais organizações e indivíduos que compõem os sistemas políticos nacionais. Por sua vez, caso os recursos necessários para execução desses imperativos estiverem concentrados em outros atores, as intervenções estatais tenderão a ser constrangidas e refletir os interesses destes (Giddens 200I, I60).

Dentre os mecanismos que intermedeiam o modo como a competição internacional influencia a construção do estado e a concorrência regulada destaca-se a guerra (Posen I993; Tilly I975; Tilly I985; Tilly I996; Herbst 
2000; Centeno 2002; Hui 2005).

Charles Tilly, por exemplo, argumenta que a evolução dos Estados-nação na Europa no período de $990-1990^{46}$ foi resultado dos esforços dos governantes para monopolizar os meios de coerção internamente e enfrentar a competição internacional (Tilly I996). Compelidos por ameaças externas, os estados aumentaram a extração de recursos dos demais componentes dos $\mathrm{SPN}^{47}$. Na medida em que tais agentes resistiam às investidas estatais, barganhavam-se condições para o fornecimento dos recursos ${ }^{48}$. Assim, em troca dos meios materiais e humanos necessários para as guerras, a organização estatal concedia direitos políticos e/ou sociais, modificando as ordens reguladoras dos SPN.

No entanto, houve variações regionais nas trajetórias de construção dos Estados-nação. O autor aponta como fator responsável por essas distinções as diferenças de capacidade estatal que cada governante possuía para impor sua dominação sobre os detentores de capital em cada território. Essa diferença teria sido responsável por alterações em duas dimensões: como eram extraídos os recursos; e quais as características das ordens que regulavam o comportamento das unidades. Três tipos ideais de trajetória seriam observáveis: intensiva em coerção, altamente capitalizada e uma trajetória ótima (do ponto de vista do Estado-Nação), de coerção capitalizada (Tilly I996, 203),

Em um extremo, nas áreas predominantemente agrícolas, poucas cidades e com pouco capital (Rússia, Hungria, Polônia, Suécia, Sicília e Castela), governantes utilizaram estratégias intensivas em coerção para extrair

46 É importante salientar que a análise de longos processos temporais engendra como fraqueza a omissão de eventos específicos nas trajetórias evolutivas de cada caso. Reconhece-se que tais eventos contingentes em certas ocasiões desempenham um papel decisivo na determinação de qual organização triunfaria em detrimento da outra. Contudo, considera-se que os mecanismos de seleção derivados da estrutura do sistema político internacional europeu atuaram de modo geral independente de tais acidentes, incentivando a centralização do poder político em estados maiores. Sobre as vantagens e desvantagens de avaliar longos processos temporais, ver Tilly (I983).

47 Ainda que, ao final do período avaliado pelo autor, esse processo tenha impulsionado a convergência dos formatos das organizações políticas europeias em direção ao Estado-nação, essa trajetória não teria ocorrido de maneira linear. De fato, houve a formação de organizações políticas com características extremamente variadas. cidades-estado, ligas de cidades, reinos, potentados eclesiásticos e impérios coexistiram no sistema político internacional europeu. Ver Spruyt (1994).

48 De acordo com Kliemt e Ahlert (2013, 47), barganhas ocorrem quando: "humanos estão engajados em 'cooperação antagonista' e precisam negociar acordos em temas como preços, salários e regulação de relações pessoais, de grupo e internacionais. As partes em barganha possuem interesses parcialmente opostos e precisam negociar como os adequar à vantagem de todos". Sobre a relação entre barganha, taxação e formação do estado, ver Moore $(2008,37)$. 
recursos, realizar guerras e controlar a ordem em seus territórios ${ }^{49}$. O enfrentamento da competição internacional era financiado por meio da exploração de uma massa camponesa submetida a uma ordem reguladora mantida mais pela aliança entre governantes, proprietários de terra e funcionários estatais (Tilly I996, 213).

Em outro extremo, nas áreas com redes densas de cidades e abundância de capital (Flandres, norte da Itália e Países Baixos), governantes empregaram estratégias intensivas em capital. A presença de uma poderosa classe mercante estabelecia "sérios limites ao exercício direto, por parte do estado, de controle dos indivíduos e das famílias, mas facilitava a aplicação de taxas relativamente eficientes e indolores sobre o comércio" (Tilly I996, I6I) s $^{50} \mathrm{Na}$ ausência de zonas agrícolas, os conflitos em que tais estados se envolviam eram custeados por empréstimos, taxas alfandegárias e impostos sobre o consumo. O controle das rotas de comércio era definido em rápidas batalhas travadas por forças mercenárias de baixo custo. Tais meios não exigiam grandes aparatos burocráticos, sendo administrados por funcionários das famílias de comerciantes e banqueiros. Logo, a preparação para a competição internacional e a ordem reguladora era sustentada por lucros comerciais e financeiros (Tilly i996, 223).

Em posição intermediária estavam os governantes que utilizaram estratégias de coerção capitalizada (Inglaterra, França e Prússia). Nesses casos, havia menor assimetria entre proprietários de terra, comerciantes e pequenos burgueses em cidades. O maior equilíbrio garantiu menor dependência dos aspectos coercitivos na atividade extrativa - em comparação as estratégias de coerção intensiva - ao mesmo tempo em que resultou em maior capacidade estatal de penetração na sociedade - em comparação aos governantes que adotaram estratégias intensivas em capital. Consequentemente, a ordem reguladora nesses SPN contava "com a aquiescência tanto dos proprietários de terras quanto dos mercadores" e estabelecia uma concorrência regulada na qual "os nobres enfrentavam os financistas, mas no final acabavam colaborando com eles" (Tilly I996, I6I). Por fim, Tilly (I996, 268) afirma que esse tipo de estado predominou sobre os outros devido a sua maior capacidade de

49 De acordo com Tilly, o caso russo constitui o modelo ideal da estratégia intensiva em coerção. Após o czar Ivan IV (I533-84) vencer os conflitos com a nobreza agrária, ele teria passado a beneficiar os funcionários do estado com as terras expropriadas. Em um segundo momento, os proprietários agrários e os agentes estatais se alinharam em torno da exploração da mão de obra camponesa. Por meio de decretos imperiais, os camponeses eram fixados ou transferidos para territórios determinados. Em I700, Pedro, o Grande, lançou decreto segundo o qual todo servo libertado devia apresentar-se imediatamente ao serviço militar e, se fosse recusado, devia se sujeitar a outro senhor (Tilly I996, 212).

50 Nesse caso, a trajetória de Veneza é o caso ideal apresentado pelo autor. 
sustentar exércitos com seus próprios recursos.

A hipótese do modelo de Tilly é de que a competição internacional foi intermediada pela forma como a concorrência regulada e a construção do estado - representadas pelas interações entre classes mercantis, nobreza agrária, camponeses e agentes estatais - estava estruturada em cada região (Tilly ı996, 76). Além disso, sugere que a consolidação do Estado-nação enquanto unidade predominante no sistema não era a única trajetória possível de evolução (Spruyt ı994). Isto é, ainda que o incremento da competição internacional induziu à mobilização de recursos pelas unidades, houve um lapso temporal até que o mecanismo da socialização operasse para convergir as ordens reguladoras dos SPN (Tilly i994, 94).

Se a variação nas relações entre coerção e capital é apontada como causa da divergência inicial nos processos de formação dos Estados-nação, as transformações no formato das forças militares e policiais seriam as responsáveis pela convergência subsequente (Finer I975; Tilly ı975; Paret I986) ${ }^{51}$. Isto é, se inicialmente a competição internacional induziu à mobilização de recursos, após as transformações nos meios que sustentavam o emprego da força o mecanismo da socialização selecionou as organizações políticas cujas reformas melhor se adequaram a tais mudanças.

Em primeiro lugar, houve aumento na escala dos recursos utilizados na competição internacional. De acordo com Mann (I993, 37I, tradução nossa), "estados lutaram guerras centrais durante dois terços do tempo, comprometendo progressivamente maiores demandas de poder humano, taxação e produção industrial e agrícola" ${ }^{52}$. Assim, o número de combatentes aumentou consistentemente. Nesse contexto, evidenciou-se que forças armadas formadas apenas por cavaleiros da nobreza e mercenários não eram capazes de enfrentar exércitos compostos por milhares de soldados conscritos, treinados e disciplinados (Jones I987, I50). Por conta disso, gradualmente o estabelecimento de forças conscritas e permanentes se impôs (Porter I994).

Em segundo lugar, a entrada das massas nos teatros de operações foi possibilitada por inovações tecnológicas nos equipamentos militares que diminuíram a predominância da nobreza nos combates. Cartuchos mais leves, bem como as invenções do mosquete, da espingarda e da baioneta aumenta-

5I Seguir-se-á o modelo proposto por Finer $(\mathrm{I} 975,90)$, que considera que o "formato das forças militares" consiste em duas dimensões: i) o recrutamento e a forma de serviço dos soldados: se são nativos ou estrangeiros, pagos ou voluntários, ad hoc ou permanentes; e ii) o tamanho das forças armadas, a composição das armas e a estratificação social da força.

52 Além disso, o número de mortes por combate aumentou de três mil por ano no século XVI, para mais de 223 mil por ano durante o século XX (Tilly I996, I3I) 


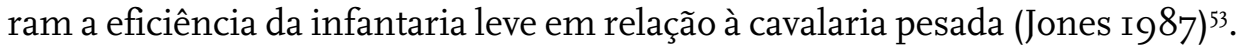
A difusão da pólvora ampliou o alcance da artilharia e diminuiu a importância dos castelos como fortificações militares (Giddens 200I, I32).

A natureza dos novos equipamentos requisitava maior padronização das ações coletivas, o que, por sua vez, exigia disciplina, hierarquia e treinamento constante dos soldados em tempos de paz (Finer I975) ${ }^{54}$. As conquistas dos estados que adotaram tais medidas pressionavam seus adversários a lhes emularem (Black I99I). Consequentemente, "o comando militar moderno emergiu no cenário europeu, extremamente disciplinado e concebido como um pilar essencial da autoridade do estado" (Porter I994, I62, tradução nossa).

Tanto pela necessidade de suprir e coordenar contingentes maiores, quanto pelo imperativo da produção em massa de equipamentos, os custos financeiros e as exigências logísticas, estratégicas e operacionais da guerra se expandiram (Finer 1975) (5) $^{5}$ Tais necessidades induziram ao aumento na capacidade de intervenção dos estados sobre os SPN. De acordo com Michael Mann (I993, 369, tradução nossa): "no final do século XVIII os estados tinham a maior capacidade de extração fiscal que o mundo havia visto até o início das guerras do século XX”. Bruce Porter (I994, I66) assinala que nesse período "departamentos de finança, envolvidos nos custos espirais das guerras, passaram por drásticas reformas e racionalização" 56 . Desse modo, a preparação para as guerras interestatais produziu como consequência estados

53 De acordo com Barry Posen: “a proliferação do uso de 'ordem aberta' parece ter ocorrido rapidamente após a revolução, persistindo em algum grau na maioria dos exércitos europeus. Era difícil enfrentar os franceses sem adotar seus métodos” (Posen I993, 94).

54 Black (I99I, 83, tradução nossa) considera que "a capacidade de atacar antes e duro, como a França fez contra os holandeses em I672 e contra a Áustria em I773, bem como a Prússia fez contra a Áustria em I740 produzia benefícios óbvios aos governantes que mantinham exércitos durante períodos de paz. Suas ações eram observadas com preocupação por outros poderes, e somente eles possuíam realmente liberdade de ação nas relações internacionais. Como resultado, havia pressões consideráveis para que certos estados aumentassem o nível de preparação militar, algo extremamente custoso". Por sua vez, de acordo com Finer (I975, 99), as primeiras forças militares permanentes surgiram em I445 na França, em i645 na Inglaterra, em i66o na Prússia e em I707 na Rússia.

55 Posen $(1993,83)$ argumenta que a essência do exército de massa é sua capacidade de manter o poder de combate em face aos desafios impostos pelo atrito nas campanhas. Assim, não apenas os imperativos de comando, controle e logística são enormes, como também a manutenção da motivação política, a educação e o treinamento de vastos contingentes são desafios para os agentes estatais.

56 Segundo Mann (1993, 393), o percentual de funcionários estatais em relação ao total da população entre I760 e I9I0 aumentou de ०,06\% para I,I7\% na Áustria, de 0,26\% para I,4\% na França, de o,I $8 \%$ para $0,64 \%$ na Inglaterra e de $0,33 \%$ para I, $57 \%$ na Prússia/Alemanha. 
com aparatos administrativos cada vez mais robustos.

As alterações nos recursos necessários para o enfrentamento da guerra na Europa evidenciaram que a sobrevivência dos estados dependia da extração de recursos provenientes de todo o SPN (Hobsbawm I992). Consequentemente, alteraram-se também os parâmetros da competição entre estados, indivíduos e organizações não estatais. Por um lado, o menor papel da nobreza nas guerras aumentou a autonomia dos agentes estatais em relação a esse grupo (Kennedy i989). Isto é, "a guerra tomou um rumo que fez da soberania fragmentada e de pequena escala uma clara desvantagem" (Tilly I996, I2I). Logo, a capacidade de as aristocracias manterem forças armadas independentes dos governos centrais se deteriorou (Black I99I, 83)57. Assim, consolidou-se a tendência de centralização dos meios de força em unidades políticas com maior extensão territorial.

Por outro lado, a participação das massas nos combates induziu à reformulação dos termos nos quais a dominação estatal se legitimava. Os efeitos foram a emergência do ideal nacional enquanto fonte de legitimidade; e o aumento das demandas civis sobre os estados, incluindo, no limite, a ação revolucionária das massas trabalhadoras anteriormente subalternas (Hobsbawm I992). Isto é, se o nacionalismo foi operacionalizado pelos governantes europeus como ferramenta de mobilização e homogeneização ideológica das populações dentro de seus territórios, ele também serviu como justificativa para reivindicações pela extensão do acesso a direitos civis, políticos e sociais nas ordens reguladoras (Marshall I973) ) $^{5}$. O contraste entre o discurso do Almirante Nelson antes da batalha de Trafalgar em i808: "a Inglaterra espera que todo homem cumpra seu dever" (Hobsbawm I992, I50), com o slogan "um homem, um voto, uma arma", difundido durante os conflitos em torno da extensão do sufrágio na Suécia no início do século XX (Bendix I976, II5), ilustra a relação existente entre mobilização militar em massa, ideal nacional e o incremento das demandas sobre o estado.

Portanto, se as reformas nesse período aumentaram a capacidade de intervenção estatal no SPN, elas também alteraram a correlação de forças en-

57 De acordo com Black (I991, 83, tradução nossa), "os exércitos mantidos pelos poderes mais fracos não se comparavam aos dos estados maiores, sendo o aumento dessa discrepância um dos desenvolvimentos militares e políticos fundamentais do período pós I660”.

58 T. H. Marshall (I973) distingue três tipos de direitos de cidadania: civis, políticos e sociais. Direitos civis seriam aqueles que garantiriam a liberdade de associação, fala e justiça em relação às acusações de comportamento inadequado. Direitos políticos tratam da participação dos indivíduos no exercício do poder político. Direitos sociais se referem à prerrogativa de cada indivíduo possuir padrões mínimos de segurança e bem-estar econômico dentro do SPN. 
tre os agentes envolvidos na concorrência regulada ${ }^{59}$. Bendix $(1978,28)$ argumenta que, enquanto a administração pública se ampliava, o acesso às posições oficiais se separava de critérios hereditários ou de propriedade. Outros autores notam que políticas de unificação linguística ${ }^{60}$ foram acompanhadas da instauração de sistemas públicos e gratuitos de educação (Posen I993). Michael Mann (I993) destaca que os gastos estatais com educação e bem-estar entre i870 e i9ı aumentaram 500\% na França, 399\% na Alemanha e 638\% no Reino Unido. Benedict Anderson (2008) avalia que o desenvolvimento da imprensa não só aumentou a capacidade de difusão de códigos de lei, emissão de relatórios e coleta de informações, mas também reforçou a identidade nacional por meio dos meios de comunicação de massa. Por sua vez, Helleiner (1998) e Lauer (2008) demonstram como a criação de moedas nacionais facilitou a tributação, aumentou a capacidade de intervenção na economia e difundiu mensagens com conteúdo nacional. Em outras palavras, da conjunção entre transformações tecnológicas e as estratégias de controle e mobilização social utilizadas pelos governantes emergiram as condições que transformaram os súditos em cidadãos da nação.

Desse modo, as consequências das preparações para a competição no SPI europeu durante o século XIX engendraram uma tendência não apenas de aumento da centralização da autoridade política nos SPN, mas também de transferência do controle do monopólio dos meios de força e da ordem reguladora da esfera privada - monarquia e a nobreza - para a esfera pública (Elias I993) ${ }^{6}$. Ou seja, por meio de medidas que ampliavam a participação

59 Para avaliação detalhada do processo de centralização da administração pública e dos meios de força nas organizações políticas estatais durante esse período, ver Bendix (I976), Elias (I993), Giddens (200I). Reproduz-se aqui o trecho da obra de Reinhard Bendix (I976) que resume a distinção fundamental entre o modo como as ordens reguladoras se sustentavam no período medieval e nos Estado-nação: “Na concepção medieval o pilar da ordem social é o privilégio hereditário familiar, cuja estabilidade ao longo do tempo é a fundação do direito e da autoridade, enquanto que a ordem estamental da sociedade e sua transmissão regula as relações entre as famílias e o governante supremo. O Estado-nação moderno pressupõe que o elo entre a autoridade governamental e os privilégios hereditários controlados pelas famílias nobres é quebrado" (Bendix 1976, 138).

60 Conforme assinala Posen (I993, I20, tradução nossa): “a alfabetização em massa torna possível que os estados treinem exércitos maiores durante os períodos de paz, bem como de os mobilizar para a guerra com maior rapidez. Além disso, torna os soldados mais acessíveis à propaganda, tanto crianças quanto adultos, o que facilita a proliferação da ideologia nacionalista".

6r Norbert Elias descreve tal processo como: “o monopólio privadamente possuído por um único indivíduo ou família cai sob o controle de um estrato social mais amplo e se transforma, como órgão central do Estado, em monopólio público" (Elias I993, IOI). Anthony Giddens, por sua vez, salienta que "ao mesmo tempo que o caminho em direção à soberania gera uma centralização dos recursos nas mãos dos governantes, ele estimula uma consciência generalizada 
política da população; burocratizavam o aparato administrativo; e expandiam os gastos e funções sociais dos estados "os regimes obtinham dos camponeses e trabalhadores uma lealdade ao Estado-nação universal, em contraposição a lealdade privada as nobrezas locais que ocorriam nas sociedades agrárias" (Mann I993, 50I, tradução nossa).

Também aqui vale resumir a relação entre agentes, estrutura e variáveis exógenas no processo de formação dos Estados-nação na Europa. Em um primeiro momento, estados com distintas estratégias de mobilização de recursos e ordens reguladoras (A) coexistiam no continente. Em uma segunda etapa, a escala dos recursos necessários para se enfrentar os constrangimentos impostos pela estrutura do SPI europeu (E) se altera em função de inovações tecnológicas e organizacionais no formato das forças militares. Por fim, o mecanismo da socialização-seleção elimina as unidades incapazes de se adequar às novas exigências da competição internacional, consolidando o Estado-nação como organização política predominante no SPI europeu (A').

Concluindo, considera-se que duas hipóteses estão implícitas no modelo explicativo de Tilly. A primeira é que o modo como a competição nos SPN europeus estava delimitado durante o período medieval constrangeu as opções de estratégias utilizadas pelos governantes para enfrentar a competição internacional. Assim, nota-se que a trajetória das interações que determinaram a evolução da estrutura do SPI europeu foi dependente do curso de eventos ocorridos anteriormente dentro de cada sistema político nacional. Ademais, o longo período de coexistência entre estados com ordens reguladoras e estratégias de mobilização de recursos distintas sugere a dificuldade (e eventual indesejabilidade) de se estabelecer modelos ideais de organização política. De fato, foram necessárias variações exógenas para que o mecanismo da socialização-seleção fizesse convergir o formato das forças militares e consolidasse o Estado-nação como unidade predominante no sistema.

A segunda é que uma variável exógena - inovação tecnológica dos sistemas militares - gerou efeitos nas dimensões de construção do estado e da concorrência regulada. O aumento na escala dos recursos necessários e as mudanças na natureza dos equipamentos tornaram a participação das massas nas guerras condição necessária para a sobrevivência no SPI europeu. Por conta disso, alterou-se a correlação de forças entre os governantes, organizações não estatais e indivíduos: diminuiu-se a influência da nobreza sobre o estado; surgiram condições para a reivindicação da ampliação de direitos civis, políticos e sociais nas ordens reguladoras; e o nacionalismo se consolidou

de que o poder político depende de capacidades coletivas, que a figura do monarca talvez possa simbolizar, mas para a qual os adornos tradicionais do domínio real têm pouca relevância" (Giddens 200I, 2I7). 
enquanto fonte de legitimidade da dominação estatal.

A análise simultânea dos processos contemporâneos de competição internacional e nacional permitiria, pois, compreender melhor como os mecanismos envolvidos (especialmente a guerra) estão produzindo a emergência de novas ordens reguladas, estruturas de autoridade, e mesmo alterando ou não a própria natureza do sistema internacional.

\section{Conclusão}

O artigo investigou a ontologia dos sistemas políticos internacionais, sistemas políticos nacionais e estados, bem como os efeitos que a competição entre seus respectivos agentes produz em seus processos evolutivos. Para tanto, recorreu-se à revisão crítica de categorias teóricas provenientes de três áreas de conhecimento: da Teoria das Relações Internacionais, da Sociologia Histórica e dos Estudos Estratégicos. O modelo resultante procurou integrar os constrangimentos impostos pela estrutura do SPI, os condicionantes da dominação estatal nos SPN e o papel do uso e da ameaça do uso da força na competição internacional.

Partiu-se do pressuposto que tanto os SPI quanto os SPN são sistemas abertos. Logo, a relação entre unidades, estrutura e variáveis exógenas não é determinística em qualquer sentido. Somente é possível integrar análises sobre o papel da agência com avaliações sobre os constrangimentos e incentivos estruturais se forem reconhecidos os limites epistemológicos e o caráter contingente da evolução histórica dos sistemas sociais (Braumoller 2OI2).

$\mathrm{Na}$ primeira seção, defendeu-se a pertinência dos conceitos de anarquia e baixa especialização funcional presentes no modelo de SPI de Waltz (I979). Considerou-se que esses dois elementos não implicam a ausência de relações hierárquicas ou cooperativas entre os estados, mas sim que tais interações assimétricas são condicionadas pela distribuição de poder e permeadas pela incerteza comportamental entre os agentes. Ou seja, a política internacional continua sendo "o reino do poder, da disputa e da acomodação" (Waltz I979, II2). No entanto, também se argumentou que esses elementos não limitam as possíveis trajetórias de evolução dos sistemas políticos internacionais, mas sim habilitam múltiplas vias. Desse modo, não há nada que assegure a reprodução de um sistema político anárquico ao longo do tempo. De fato, o resultado da interação entre estados, variáveis exógenas e mecanismos concorrentes pode favorecer tanto a descentralização quanto a concentração dos meios de força. Para exemplificar o argumento, retomou- 
se o modelo explicativo de Hui (2005) sobre o processo de transformação do SPI formado por reinos chineses em 656 a.C., em um SPN dominado pela Dinastia Qin em 22I a.C. Afinal, os rivais do Reino Qin também eram organizações políticas que objetivavam sobreviver em um sistema anárquico. Contudo, os mecanismos de restauração da descentralização de poder não foram suficientes para impedir a integração do sistema. Naquele contexto, as reformas fortalecedoras e estratégias de desestabilização das alianças tornaram a concentração dos meios de coerção um processo de reforço positivo.

Na segunda seção, analisou-se o efeito da competição internacional no processo evolutivo dos estados e sistemas políticos nacionais. Considerouse que a concentração dos meios de coerção em uma unidade específica o estado - altera os meios utilizados na competição entre os agentes que formam os SPN. De acordo com os atores e meios envolvidos, três dimensões de conflito foram delimitadas: competição internacional entre as unidades dos SPI; construção do estado; e concorrência regulada entre as organizações não estatais e indivíduos em torno das oportunidades específicas de vida nos SPN centralizados em Estados nacionais. Argumentou-se que a preparação dos agentes e o resultado dos embates em cada dimensão gera consequências para a evolução dos objetos de análise nas demais dimensões. Ao final, avaliou-se a formação dos Estados-nação na Europa a partir do modelo explicativo proposto por Tilly (I996). Naquele caso, as formas pelas quais a construção do estado e a concorrência regulada se estabilizaram constrangeram as estratégias à disposição dos governantes para enfrentar a competição internacional posteriormente; o longo período de coexistência entre estados com ordens reguladoras e estratégias de mobilização de recursos distintas sugeriu a impossibilidade do estabelecimento de modelos ideais de organização política; e variações tecnológicas e organizacionais no formato das forças militares que competem no SPI geraram efeitos sobre a construção do estado e a concorrência regulada.

Por fim, conclui-se que a agenda de pesquisa que se debruça sobre os requisitos necessários para a "defesa do estado" deve ser indissociável de discussões sobre "para que $(\mathrm{m})$ serve o estado". Além disso, a análise realizada indica a progressividade do seguinte problema de pesquisa: em que condições as interações competitivas entre os agentes contribuem para o surgimento de organizações políticas capazes de sobreviverem, atuarem no sistema político internacional e proverem segurança, bem-estar e direitos políticos para seus cidadãos? Esta continua sendo uma questão política central no século XXI. 


\section{REFERÊNCIAS}

Abbott, Russ. 2006. “Emergence Explained: Abstractions: Getting Epiphenomena to Do Real Work". Complexity I2 (I): 13-26.

Anderson, Benedict. 2008. Comunidades Imaginadas: Reflexos sobre a Origem e a Difusão do Nacionalismo. São Paulo: Companhia das Letras.

Archer, Margaret. 20I5. Generative Mechanisms Transforming the Social Order. New York: Springer.

Arrighi, Giovanni. 20I0. The Long Twentieth Century: Money, Power and Origins of Our Time. London: Verso.

Bendix, Reinhard. I976. Nation-Building and Citizenship: studies of our changing social order. London: University of California Press.

Kings or People: Power and the Mandate to Rule. Berkeley: University of California Press.

Bertuglia, Sergio, and Franco Vaio. 2005. Nonlinearity, Chaos, and Complexity: the dynamics of natural and social systems. New York: Oxford University Press.

Bhaskar, Roy. I998. “The Logic of Scientific Discovery”. In Critical Realism: essential readings. London: Routledge.

Bianchi, Alvaro. 20I4. "O Conceito de Estado em Max Weber". Lua Nova (92): 79-IO4.

Black, Jeremy. I99I. A Military Revolution? Military Change and European Society 1550-1800. London: Macmillan Press.

Boulding, Kenneth. I962. Conflict and Defense: A General Theory. New York: Harper and Brothers.

Braumoller, Bear. 2012. The Great Powers and International System: an empirical systemic theory perspective. New York: Cambridge University Press.

Buzan, Barry. 1984. People, States and Fear: the National Security Problem in International Relations. London: Harvester Press Group.

Buzan, Barry, and Richard Little. 2000. International Systems in World History: remaking the study of international relations. New York: Oxford University Press.

Carlsnaes, Walter. I992. "The Agency-Structure Problem in Foreign Policy Analysis". International Studies Quarterly 36 (3): 245-270.

Centeno, Miguel. 2002. War and the Nation-State in Latin America. University Park: The Pennsylvania State University Press.

Cepik, Marco. 1999. "Para uma Sociologia Histórica das Revoluções Modernas”. 
Revista Teoria \& Sociedade 3: I29-I62.

Checkel, Jeffrey. 2006. “Tracing Causal Mechanisms". International Studies Review 8 (2): 362-370.

Clarke, Simon. I99I. "Overaccumulation, class struggle and the regulation approach". In Post-fordism \& social form: a Marxist debate on the postfordist state. London: MacMillan Press.

Cusack, Thomas, and Richard Stoll. I994. "The security predicament: Assessing the effectiveness of realist and idealist principles in interstate politics". International Studies Quarterly 38: 33-59.

Dahl, Robert. 1961. Who governs? Democracy and power in an American city. New Haven: Yale University Press.

Doyle, Michael. I986. "Liberalism and World Politics". The American Political Science Review 80 (4): II5I-II69.

Elias, Norbert. I993. O Processo Civilizador Volume 2: formação do Estado e Civilização. Rio de Janeiro: Jorge Zahar Editor.

Elster, Jon. 1989. "Social Norms and Economic Theory". The Journal of Economic Perspectives 3 (4): 99-II7

Finer, Samuel. 1975. "The state and nation-building in Europe: the role of the military". In The Formation of National States in Western Europe. Princeton: Princeton University Press.

Friedman, Gil, and Harvey Starr. 1997. Agency, Structure, And International Politics From ontology to empirical inquiry. London: Routledge.

Geuss, Raymond. 200I. History and Illusion in Politics. Cambridge: Cambridge University Press.

Giddens, Anthony. 200I. O Estado Nação e a Violência: Segundo volume de uma crítica contemporânea ao materialismo histórico. São Paulo: Editora da Universidade de São Paulo.

Gilpin, Robert. I98I. War and Change in World Politics. Cambridge: Cambridge University Press.

Grzymala-Busse, Anna. 20II. "Time Will Tell? Temporality and the Analysis of Causal Mechanisms and Processes". Comparative Political Studies 44 (9): $1267-1297$.

Hardin, Garret. 1963. "The Cybernetics of Competition: a Biologist's view of society". Perspectives in Biology and Medicine 7 (I): 58-84.

Hay, Colin, and Daniel Wincott. I998. "Structure, Agency and Historical Institutionalism". Political Studies 46 (5): 95I-957.

Hedström, Peter, and Petri Ylikoski. 2oro. "Causal mechanisms in the social 
sciences". Annual Review of Sociology 36 (I): 49-67.

Helleiner, Eric. I998. "National Currencies and National Identities". American Behavorial Scientists 4I (10): I409-I436.

Herbst, Jeffrey. 2000. States and Power in Africa: comparative lessons in authority and control. New Jersey: Princeton University Press.

Hobsbawm, Eric. I992. Nations and Nationalism since 1780: programm, mith Q reality. Cambridge: Cambridge University Press.

Holland, John. 2012. Signals and Boundaries: Building Blocks for Complex Adaptive Systems. Cambridge: MIT Press.

Hui, Victoria Tin-bor. 2005. War and state formation in ancient China and early modern Europe. Cambridge: Cambridge University Press.

Jaccard, James, and Jacob Jacoby. 2009. Theory Construction and Model-Building Skills. A Practical Guide for Social Scientists. New York: The Guilford Press.

Jervis, Robert. I997. System Effects: complexity in political and social life. New Jersey: Princeton University Press.

Jones, Archer. 1987. The Art of War in the Western World. New York: Oxford University Press.

Kennedy, Paul. I989. The Rise and Fall of the Great Powers: Economic Change and Military Conflict from 1500 to 2000. London: Unwyn Himan.

Kiser, Edgar, and Yong Cai. 2003. "War and Bureaucratization in Qin China: Exploring an Anomalous Case”. American Sociological Review 68 (4): 5II-539.

Kliemt, Hartmut, and Marlies Ahrlet. 2013. "Bargaining Theory”. In Encyclopedia of Philosophy and Social Science. London: Sage.

Lauer, Josh. 2008. "Money as Mass Communication: U.S. Paper Currency and the Iconography of Nationalism". The Communication Review II (2): IO9-I32.

Levi, Lucio. 1998. “Legitimidade”. In Dicionário de Política. Brasília: Editora da Universidade de Brasília.

Levy, Jack, and William Thompsom. 20Ir. The Arc of War: Origins, Escalation, and Transformation. Chicago: The University of Chicago Press.

Lewis, Mark. I990. Sanctioned Violence in Early China. Albany: State University of New York Press.

. 2006. "The Just War in Early China". In The Ethics of War in Asian Civilizations. London: Routledge. . 2007. The Early Chinese Empires: Qin and Han. London: Harvard Uni- 
versity Press.

Lockwood, David. I956. "Some Remarks on the Social System". The British Journal of Sociology 7 (2): I34-I46.

Lukes, Steven. 2004. Power: A radical view. Houndmills: Palgrave Macmillan.

Lustick, Ian. 20II. "Taking Evolution Seriously: Historical Institutionalism and Evolutionary Theory". Polity 43 (2): 179-209.

Mann, Michael. 1986. The Sources of Social Power: Volume I, A History of Power from the Beginning to $A D$ 1760. Cambridge: Cambridge University Press.

. I992. States, War and Capitalism: studies in political sociology. Oxford: Blackwell.

. 1993. The Sources of Social Power Volume II: the rise of classes and nation states: 1760-1914. Los Angeles: Cambridge University Press.

Marshall, Thomas Humphrey. I973. Class, Citizenship and Social Development. Westport: Greenwood Press.

Matteucci, Nicola. I998. “Contratualismo”. In Dicionário de Política. Brasília: Editora da Universidade de Brasília.

Maturana, Humberto, e Francisco Varela. 2005. A árvore do conhecimento: as bases biológicas da compreensão humana. São Paulo: Palas Athena.

Mearsheimer, John. 200I. The Tragedy of Great Power Politics. New York: Norton.

Mitchell, Melanie. 2009. Complexity: a guided tour. New York: Oxford University Press.

Moore, Mick. 2008. "Between coercion and contract: competing narratives on taxation and governance". In Taxation and State Building in Developing Countries. New York: Cambridge University Press.

North, Douglas, John Wallis, and Barry Weingast. 2009. Violence and Social Order: a conceptual framework for interpreting recorded human history. Cambrigde: Cambridge University Press.

Paret, Peter. 1986. "Napoleon and the Revolution of War". In Makers of Modern Strategy: from Machiavelli to the nuclear age. New Jersey: Princeton University Press.

Pasquino, Gianfranco. I998. “Conflito”. In Dicionário de Política. Brasília: Editora da Universidade de Brasília.

Pierson, Paul. 2000. "Increasing Returns, Path Dependence, and the Study of Politics”. American Political Science Review 94 (2): 25I-267. 2004. Politics in Time: history, institutions and social analysis. New Jer- 
sey: Princeton University Press.

Porter, Bruce. I994. War and the Rise of the State: the military foundations of modern politics. New York: The Free Press.

Posen, Barry. I993. "Nationalism, the Mass Army, and Military Power". International Security I8 (2): 80-I24.

Prigogine, Ilya, and Isabelle Stengers. I984. Order out of Chaos: Man's new dialogue with nature. New York: Bantam Books.

Reis, Bruno. I997. Modernização, Mercado e Democracia: Política e Economia em Sociedades Complexas. Rio de Janeiro: IUPERJ.

. 2003. "O Mercado e a Norma: o Estado moderno e a intervenção pública na economia”. Revista Brasileira de Ciências Sociais I8 (52).

Rosenau, James. I997. Along the Domestic-Foreign Frontier: Exploring Governance in a Turbulent World. Cambridge: Cambridge University Press.

Rosenstein, Nathan. 2009. "War, State Formation, and the Evolution of Military Institutions in Ancient China and Rome". In Rome and China Comparative Perspectives on Ancient World Empires. New York: Oxford University Press.

Schweller, Randall. 2004. "Unanswered Threats: A Neoclassical Realist Theory of Underbalancing”. International Security 29 (2): I59-20I.

Spruyt, Hendrik. I994. The Sovereing State and Its Competitors. New Jersey: Princeton University Press.

Stein, Howard. 2008. Beyond the Institutional Agenda: an institutional approach to development. London: The University of Chicago Press.

Thelen, Kathleen. 2003. "How Institutions Evolve: insights from comparative historical analysis". In Comparative Historica Analysis in the Social Sciences. New York: Cambridge University Press.

Tilly, Charles. I975. The Formation of National States in Western Europe. Princeton: Princeton University Press.

. 1983. Big Structures, Large Process, Huge Comparison. Michigan: Russel Sage Foundation.

. I985. "War making and state making as organized crime". In Bringing the state back in. Cambridge: Cambridge University Press.

. 1993. European Revolutions, 1492 - 1992. New Jersey: Wiley-Blackwell.

. I994. Cities and the Rise of States in Europe, A.D. 1000 to 1800. Boulder: Westview Press.

. I996. Coerção, capital e estados europeus. São Paulo: EDUSP.

Tilly, Charles, and Robert Goodin. 2006. "It Depends". In The Oxford Hand- 
book of Contextual Political Analysis. Oxford: Oxford University Press.

Vasconcellos, Maria José Esteves. 20I3. Pensamento Sistêmico: o novo paradigma da ciência. Campinas: Papirus.

Waltz, Kenneth. I979. Theory of International Politics. Reading: Addison-Wesley Publishing Company.

. 1986. "Reflection on Theory of International Politics: a Response to my Critics". In Neorealism and its Critics. New York: Columbia University Press.

Watson, Adam. I992. The Evolution of International Society: A Comparative Historical Analysis. New York: Routledge.

Weber, Max. I98I. A ética protestante e o espírito do capitalismo. São Paulo: UnB. . I99I. Economia e sociedade: fundamentos da sociologia compreensiva. Brasília: Editora Universidade de Brasília.

. I999. Economia e Sociedade: fundamentos da sociologia compreensiva volume 2. São Paulo: Editora UnB.

2010. Conceitos Sociológicos Fundamentais. Covilhã: Lusofia Press.

Wendt, Alexander. 1999. Social Theory of International Politics. New York: Cambridge University Press.

Wight, Colin. 2006. Agents, Structures, and International Relations: Politics as Ontology. Cambridge: Cambridge University Press.

2015. "Mechanisms and Models: Some Examples from International Relations". In Generative Mechanisms Transforming the Social Order. New York: Springer.

Wimmer, Andreas. 2006. "Models, Methodologies, and Metaphors on the Move". In Understanding Change Models, Methodologies, and Metaphors. London: Palgrave Macmillian.

Wong, Roy Bin. I997. China Transformed Historical Change and the Limits of European Experience. New York: Cornell University Press.

Zakaria, Fareed. 1998. From Wealth to Power: The Unusual Origins of America's World Role. Princeton: Princeton University Press. 


\section{RESUMO}

Conflitos são intrínsecos aos sistemas sociais e constituem uma dimensão irredutível de seu desenvolvimento. Este artigo discute os efeitos do conflito entre Estados na dinâmica evolutiva do sistema político internacional. Para tanto, discute-se a ontologia dos objetos de análise e os mecanismos causais que conectam suas respectivas trajetórias evolutivas. Em seguida, avalia-se o modelo analítico desenvolvido em relação aos casos representados pela formação do Império Qin na China e pela construção dos Estados-nação na Europa. Como se pretende demonstrar, as interações estratégicas entre os agentes são decisivas como causas de mudanças nos sistemas políticos internacionais e nos próprios agentes.

\section{PALAVRAS-CHAVE}

Sistema internacional; Construção do Estado; Estrutura.

Recebido em 13 de julho de 2017. Aprovado em 2 de agosto de 2017. 